\title{
How Should Authors Address Copyright Issues before Submission of Manuscripts?
}

\author{
Sun Huh, MD, PhD \\ Ethics Editor, Archives of Plastic Surgery
}

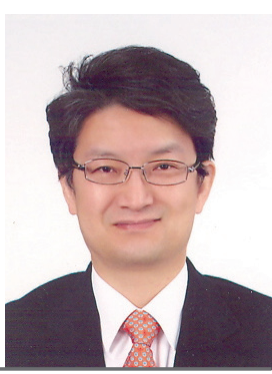

Archives of Plastic Surgery (APS), an official journal of the Korean Society of Plastic and Reconstructive Surgeons, publishes articles with many tables and figures, including illustrations, photos, videos, drawings of patients or surgical procedures. All clinical journals do the same. It is well-known that signing the Patient Photographic and Videographic Consent, Authorization and Release Form is mandatory before submitting a manuscript. This consent form is provided at the e-submission site for authors of APS. Most authors are familiar with collecting patients' consent forms; however, authors need to consider something else before submitting the form. They must determine whether there are any copyright issues due to using data from other journals or books in the authors' manuscript. This includes not only copying content exactly as it was originally printed, but also adapting or modifying previously published content. If the authors feel that previously published figures and tables are essential to their manuscript and should be copied, they must obtain permission from the original publisher. The instructions to authors of APS asserts that 'A letter of permission is required for any and all material that has been published previously. It is the responsibility of the author to request permission from the publisher for any material that is being reproduced. This requirement applies to text, illustrations, and tables.' From 1997 to $2009,50 \%$ of all science papers were published by the top 8 commercial publishing companies [1]. Therefore, reading, and occasionally using data from, the journals of those $8 \mathrm{com}$ mercial publishing companies is inevitable. To cite the tables and figures from commercial journals, authors should visit the copyright clearance center of the original journal to inquire whether it is possible to cite the tables and figures in other journals or books. Sometimes, payment is necessary to use them. When the data has appeared in a commercial journal, it is not the editors or authors who permit the use of tables or figures but the publisher. This practice holds even if the tables or figures have been modified or adapted from the original data.

Sometimes, drawings are included in the manuscript. To evade the copyright problem, it is best to draw an image that has been originally conceptualized by the authors. APS pays for professional illustration. Therefore, when authors want a new drawing, the editor can help them by introducing a professional medical illustrator. Authors should not hesitate to contact the editor to commission new drawings.

One emerging issue is synthesized photos of the face or other body part. With technical developments in digital manipulation and databases of the human body, it is common to encounter synthesized photos. Synthesized photos do not require a consent form from any of the subjects. When the authors want to use photos from another paper, permission from the publisher of the original paper is required. The process is same as described above.

How should we handle figures, photos, videos, and drawings that are widely available on the internet in cases where it is difficult to determine who is the original producer or for which there is no copyright statement? It is strongly recommended that these materials not be republished if the original author or publisher cannot be clearly identified. APS is an open access journal, which means that anyone can read the papers and view the tables and figures. If anyone finds his or her creative works published in APS without permission, it may cause loss of respect from the profession, legal problems, or even a loss of one's job, university

Copyright $(\odot 2012$ The Korean Society of Plastic and Reconstructive Surgeons

This is an Open Access article distributed under the terms of the Creative Commons Attribution Non-Commercial License (http://creativecommons.org/

licenses/by-nc/3.0/) which permits unrestricted non-commercial use, distribution, and reproduction in any medium, provided the original work is properly cited.

www.e-aps.org 
enrollment, or university diploma.

The best approach to using previously published multimedia and data is to cite content from open access journals with appropriate acknowledgment and citation. APS is also a noncommercial open access journal so that it is possible to republish the tables and figures included in APS without permission from the publisher, if the source is correctly cited. APS 'permits unrestricted non-commercial use, distribution, and reproduction in any medium, provided the original work is properly cited.' A permission request form is also available on the APS web site (http://e-aps.org) for requesting commercial use of the data. Still the proportion of open access journals, particularly among the top journals, is small. Out of 1,145 PubMed Central (PMC) journals, 843 journals are open access. However, as of July 22, 2012, the number of papers in the open access subset of 2,401,869 PMC papers was only 475,293 . This disparity has resulted from the relatively recent development of the concept of open access publication and the subsequent rapidly growing popularity of starting open access journals or converting existing journals to an open access policy. Furthermore, among open access papers, 57,382 reported results funded by National Institutes of Health $(\mathrm{NIH})$ grants, which require open access publication [2]. Since there is a public access policy in the United States, Canada, and United Kingdom, we can expect that the number of papers published in open access journals will increase annually by at least 100,000 per year from those three countries. As the proportion of open access papers increases, authors will be able to reuse media more easily without going through the process of getting permission.

Another copyright issue in publishing a paper is the use of questionnaires or other types of assessment tools to evaluate demographics, psychological state, patient progress, and other outcomes. The authors of well-designed tools have put in a great effort to test and validate these tools so that they will produce useful results, so many authors charge a fee for their use. If an assessment tool is copyrighted, the copyright owner should be paid before using it. Of course, in the paper, the assessment tool must be mentioned. Therefore, it is not difficult for the copyright owner to find it through Google Scholar and determine whether the author has paid for the use of the tools. If the author of an assessment tool, such as a questionnaire, finds evidence of use without payment, he or she can demand compensation from the author [3].

It is very difficult for a journal editor or manuscript editor to identify whether any figures, photos, videos, drawings, or tables are original or not when the authors do not mention their sources. Unlike text, there is still no simple tool to search for figures, photos, drawings or videos to check for potential duplication. The editor has no choice but to trust authors to respect the Instructions to Authors in dealing with copyright issues. However, if copyrighted data were to be published in APS without permission, who is responsible for the legal problem? Since the copyright was transferred to the Society, the Society takes the responsibility. If it is plagiarism, one of the major forms of pub-

Fig. 1. Process of getting permission from another copyright holder

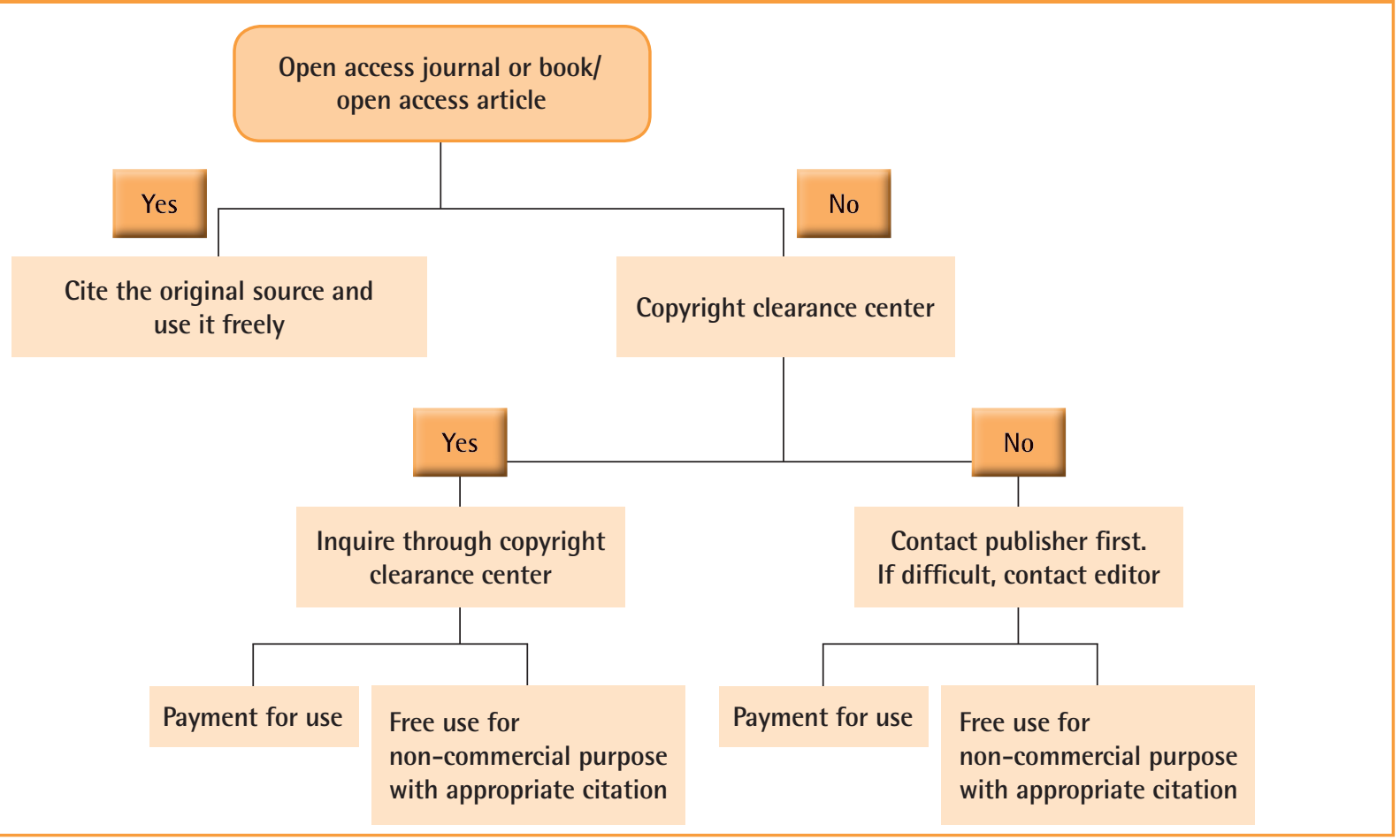


lication misconduct, the editor can announce it in the journal. If any data from a commercial journal were used without permission, the Society may be forced to pay for them. Needless to say, this does not absolve the author of collegial responsibility. If the Society is forced to deal with a copyright issue, it does not reflect well on the reputation of the author. In short, it could affect the author's career and limit future local and international publication opportunities.

Last year, there was a case of copyright issue between a medical society in Korea and an international commercial publishing company. When the society published a textbook, too many of the figures were copied from commercial journals of that company without permission. After a protest by the commercial company, a society had to revise the textbook immediately, changing all figures related to the copyright issues. If such a large commercial company were to sue an academic society, the society would be unable to handle the legal issues and associated costs. Fortunately, the company chose not to file a lawsuit. The copyright law of the government of the Republic of (South) Korea is very strong. In 2002, the Korean government signed the World Intellectual Property Organization Copyright Treaty, which is a special treaty among countries participating in the Bern Convention for the Protection of Literary and Artistic Works. Criminal laws and civic affairs support the copyright of any original works in the Republic of Korea, including works originating from anywhere in the world.
Copyright is a legal tool that can benefit us as researchers and authors. It is in our own best interests, and that of the Korean Society of Plastic and Reconstructive Surgeons, for us to understand how to protect the copyright of others' work and how to use it for their own works. A drawing of the process of getting permission to use figures or tables from other journals or books is provided to assist APS authors (Fig. 1).

\section{REFERENCES}

1. Didegah F, Gazni A. The extent of concentration in journal publishing. Learn Publ 2011;24:303-10.

2. PubMed Central [Internet]. Bethesda: U.S. National Institute of Health; 2012 [cited 2012 Jul 22]. Available from: http://pubmedcentral.org/.

3. Newman JC, Feldman R. Copyright and open access at the bedside. N Engl J Med 2011;365:2447-9.

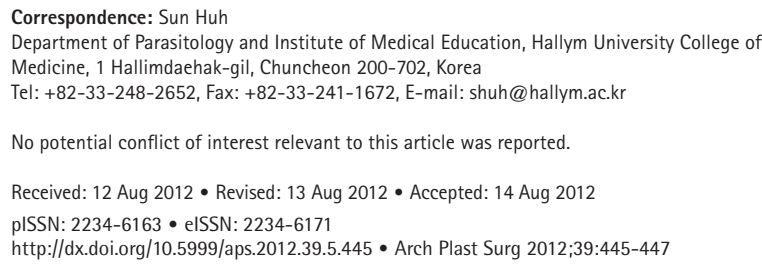

